\title{
МОДЕЛЬ ПРИНЯТИЯ ЭКОНОМИЧЕСКИХ РЕШЕНИЙ В КЛАССИЧЕСКОЙ И ИНТЕРПРЕТАТИВНОЙ ПАРАДИГМАХ: СРАВНИТЕЛЬНЫЙ АНАЛИЗ В КОНТЕКСТЕ ТЕОРИИ
}

\author{
(c) 2021 Гришина Анна Константиновна \\ аспирант Департамента экономической теории \\ Финансовый университет при Правительстве Российской Федерации, Россия, Москва \\ E-mail: joli12591@yandex.ru \\ ORCID: https://orcid.org/0000-0003-3749-3841
}

Старые институционалисты выявили неприменимость идеологии laissez-faire к сложным социально-экономическим системам. Новая институциональная теория основывается на принципах методологического индивидуализма и рациональности. Основу исследования моделей принятия экономических решений в классической и интерпретативной парадигмах составляют различие подходов к пониманию социальной реальности и природы институтов.

Ключевые слова: исходная институциональная экономика, интерпретативная парадигма, неоинституционализм, рациональность, институты, hото есопотісия, исторический метод.

Концепции морали и рациональности человеческой деятельности выступают базовыми предпосылками анализа теории социальных институтов. Начиная с «Протестантской этики...» (1905) М. Вебер развивает идею о том, что рационализация определяет процесс культурноисторической эволюции как отдельных социальных сфер и институтов, так и человечества в целом.

Различие подходов к анализу принятия экономических решений обусловило формирование двух философских позиций в экономической теории: мировоззрения, исходящего из понятия «индивид», которое сохраняет господство в мейнстриме современной экономики, и противостоящего ему коммунитаристского направления (от англ. community). Первое направление берет свое начало от классической (естественнонаучной) парадигмы, укорененной в научных сообществах Запада со времен эпохи Просвещения. Коммунитаризм восходит к немецкой историко-этической школе Г.Шмоллера, положившей начало интерпретативной парадигме в общественных науках, и впоследствии институционалистской традиции Дж. Коммонса.

$\mathrm{K}$ началу XX в. Т.Веблен и Дж. Коммонс независимо друг от друга и практически одновременно на базе холистического подхода сформулировали принципы социологического понимания институтов. Принятие предпосылки о воздействии общественных закономерностей на хозяйственные процессы позволило рас- ширить предмет экономической науки за счет включения в анализ хозяйственного поведения неэкономических феноменов.

Основоположником институциональной экономики признан Т.Веблен, рассматривавший институты как результат поведенческой привычки, компонентами которых являются правила, происходящие из культуры, в частности, духовная позиция, взгляды, предубеждения, воззрения или «распространенные представления об образе жизни в обществе», а также психологический феномен образа мысли (habits of thought) в том, «что касается отдельных отношений между обществом и личностью» [22, с. 107].

В работе «Место науки в современной цивилизации» (1919) Т.Веблен отмечает, что «основой действия - ее отправной точкой - на всех этапах процесса является органический комплекс мысленных привычек, которые были сформированы прошлым процессом» [46, с. 77]. У истоков данной мысли стоит философия прагматизма Ч.Пирса, ключевыми понятиями которой выступают «верование» (belief) и «правило действия» (rule of action), отождествляемое с привычкой (habit): «верование обладает тремя свойствами: во-первых, оно есть что-то, что мы осознаем; во-вторых, оно кладет конец раздражению, вызванному сомнением; и, в-третьих, оно влечет за собой установление в нашей природе правила действия, короче говоря, привычки» [18, с. 274-278, 305].

Следуя философии Ч.Пирса, Т.Веблен для 
своей институциональной теории делает вывод онтологического характера: человеческая деятельность протекает согласно определенным правилам, которые сохраняют стабильность до тех пор, пока действующие на их основании акторы не сомневаются в своих верованиях. Под влиянием психологических и технологических факторов («кумулятивная причинность») сомнения в сознании акторов порождают институциональные изменения - последовательная смена верований сопровождается заменой правил: «Эволюция общества является по существу процессом адаптации, происходящим под давлением обстоятельств в умах отдельных людей, уже больше не терпящих привычного образа мысли, сложившегося в прошлом. <...> Всякий человек... будет ощущать расхождение между тем способом жизни, который диктуется ему вновь возникшими потребностями, и традиционным, к которому он привык» [22, с. 107, 109].

В числе особенностей вебленовской методологии необходимо отметить, что Т.Веблен выступал современником первого поколения структурного функционализма [44], направления в социологической мысли, у истоков становления которого стоял французский социолог Э.Дюркгейм. Т.Веблен развивает мысль о том, что общество представляет собой уникальную реальность [7], и формулирует, что непропорциональный рост паразитических отраслей бизнеса оказывает негативное влияние на эффективность жизнедеятельности социума путем оказания на потребителей общественного и психологического давления, вынуждающего их к принятию неразумных решений [22].

Выражая отказ от идеологии laizzesfaire к объяснению сложных социальноэкономических систем, Т.Веблен выступает против постулата неоклассической экономической теории, утверждающей, что при принятии хозяйственных решений субъекты руководствуются соображениями рациональности и максимизации личной выгоды, закрепляя за социальными институтами ключевую роль в определении непосредственных целей экономического поведения. Между тем, сохраняя приверженность дарвинистскому подходу к анализу процессов институциональной эволюции, Т.Веблен не вышел за границы классической парадигмы Галилея-Декарта-Ньютона. C помощью подробного и последовательного эволюционного и каузального анализа
Т.Веблен стремился объяснить происхождение поведенческих характеристик человека. Он охарактеризовал применяемый им метод как генетический, который «рассматривает проявления и последовательность развития, а также пытается понять результат, изучая, почему и как это произошло» [47, с. 655].

Переход от видения мира, основанного на причинно-следственных связях, к мировоззрению, трактующему социально-экономические явления как результат следования каждым членом сообщества принятым в его рамках правилам поведения, был последовательно осуществлен историко-этической школой Г. Шмоллера и висконсинским институционализмом Дж. Коммонса [9]. Новый подход к социальному исследованию был развит на идеях герменевтики В. Дильтея (Германия) и прагматизма Ч. Пирса и Дьюи (США).

Согласно Г.Шмоллеру, под институтом «мы понимаем служащий определенным целям порядок жизни сообщества, достигнутый на некоторый момент времени, который служит рамками и формой для действий следующих друг за другом поколений» [41, с. 61-62]. В связи с тем, что хозяйственные явления зависят от культурной социализации, экономическая наука, по мнению Г.Шмоллера, не способна к выработке целостных теорий, применимых к любой историко-географической среде [8]. Следовательно, экономические процессы могут быть проанализированы только с помощью историко-эмпирического подхода.

Историю, по Г.Шмоллеру, необходимо рассматривать как процесс нравственного подъема человечества, в котором отдельной стадии эволюции соответствует качественно более высокий уровень морального развития общества. Данному прогрессивному пути Г.Шмоллер дает как биологическое, так и социологическое обоснование. Разделяя идеи эволюционной концепции Ж.Б. Ламарка, он утверждает, что производимый на каждом этапе человеческий капитал передается последующим поколениям по наследству [40]. Кроме того, Г.Шмоллер в духе «Философии денег» (1900) Г.Зиммеля замечает, что измерением нового типа реальности, основанного на разделении труда и товарно-денежных отношениях, становятся социально-анонимные связи [41]. В условиях роста личной свободы фактором общности в утилитарных действиях индивидов выступают укорененные в культуре 
черты народного этоса: находя свое воплощение в институтах - этических правилах, хозяйственных нравах и праве [25] как устоявшихся в результате «моральной жизни» матрицах поведения, «коллективный этос хозяйства» оказывает смягчающее воздействие в борьбе экономических интересов и служит целевым ориентиром в процессе принятия хозяйственных решений.

Отделение права от нравов, по Г.Шмоллеру, является необходимым условием для культурного прогресса. Положительное право закрепляет существенно важные части уклада жизни общества, которые характеризуются медленными изменениями в процессе социальной адаптации, служа «твердой опорой тому, что должно оставаться непоколебимым в интересах торговли и оборота, как и всей культурной жизни. <...> Нравами мы называем в поступках людей то, что происходит с правильным постоянством, вытекая из опыта и воспоминаний, из разумного понимания общих целей и нравственного сознания» [25, с. 137-138]. Путем изменения правовых отношений государство призвано согласовать формы хозяйства с морально-нравственными представлениями о справедливости, способствуя устранению классового неравенства.

Таким образом, говоря о социальных институтах,1Г. Шмоллер указывает на внешнюю структуру совместной жизни, которая выступает гарантом общественной безопасности и избавляет человека от постоянного принятия решений; здесь проявляется в равной мере власть общества, которому принадлежит общественное мнение как элемент социального контроля «путем возражений и порицаний сограждан», а также государственная власть, использующая в качестве мер принуждения уголовный и гражданский процесс. Но при этом, Г. Шмоллер также сознает необходимость обеспечения пространства для новаторского и адаптивного поведения, для раскрытия творческих сил и умственных способностей личности, выступающих в роли движущих факторов социальной динамики, что является центральным аргументом в пользу воспитания «духовной свободы» [39].

Центральной категорией институциональной концепции Дж. Коммонса, является теория транзакций, основанная на «совместной деятельности людей и их оценок во всех соглашениях, посредством которых участники побуждают друг друга к достижению единства мнений и действий» $[14$, с. 334]. Принимая форму сделок, достигаемых по результатам честных переговоров, экономическое действие всегда выступает как проявление коллективного действия, соединяясь с транзакциями права и этики [30].

По Дж. Коммонсу граждане, взаимодействующие друг с другом, следуют привычкам под давлением различных сообществ-организаций, членами которых они являются [29]. При этом, институты выполняют не только функцию контроля за индивидуальными действиями через механизмы санкционного воздействия, но и освобождают индивидов от принуждения, ограничения свободы, дискриминации, нечестной конкуренции со стороны других участников сообщества. Наряду с государством, гарантом правил является общество (или его неформальный представитель - общественность), стоящее у истоков институциональных изменений [11].

Дж.Ходжсон выступает с критикой методологии Г.Шмоллера и Дж. Коммонса: «Установив значимость институтов, рутин и привычек, он начал придавать особую ценность описаниям природы политико-экономических институтов и их функций <...> Роковым заблуждением были настойчивые требования... собирать как можно больше информации, либо же создавать как можно более детальные картины конкретных экономических институтов» [24, с. 53]. Тем не менее, невостребованности исходного институционализма среди современников предшествовали другие, более объективные предпосылки: отсутствие единой теоретико-методологической базы институциональных исследований, нарушение дисциплинарных границ в общественных науках ввиду использования исследователями методов юриспруденции, социологии, политологии привело к нарастанию внутренних противоречий в рамках «старой» институциональной теории. Неоинституциональный поворот рубежа 19601970-х гг. ознаменовал рождение новой ветви исследований институтов в других социальных науках, породив несколько разных направлений. Фундаментальным различием в понимании социальной реальности и природы институтов [17, с. 175] характеризуются социологический и рационалистический институционализм.

Институционализм рационального выбора берет свое начало со времен классической политической экономии. Основным инструментом анализа проблемы выбора и мотивации в хозяйственной деятельности индивидов выступает модель экономического человека, зарождение 
которой традиционно ассоциируется с именем А. Смита и его трудом «Исследование о природе и причинах богатства народов» (1776). В своем исследовании А.Смит исходит из предпосылки об универсальности природы человека, которая находит отражение в таких его врожденных, базовых и неизменных моральных свойствах, как «постоянное и неисчезающее стремление улучшить свое положение» [20, с. 62]. и склонность к обмену или торговле. Рациональность в противоположность неразумности или расточительности заключается в выборе наиболее выгодного в денежном выражении образа действий из возможных: «Дай мне то, что мне нужно, и ты получишь то, что необходимо тебе, - ... именно таким путем мы получаем друг от друга значительно большую часть услуг, в которых мы нуждаемся» [29, с. 350].

В дальнейшем тематика экономического человека получила развитие в рамках экономикс. Под влиянием, в частности, таких представителей, как К.Менгер, Л.Вальрас, У.Джевонс и др., совершивших в 1870-х гг. «маржиналистскую революцию» в экономической науке, в модель homo economicus была введена категория полезности как удовлетворения потребности или выгоды, получаемой от потребления продукта. Способность хозяйственных субъектов всегда достигать оптимального состояния, которая позволяет поддерживать всю экономику в равновесии, предполагает, что индивид располагает точным знанием хотя бы обо всех доступных ему альтернативах [6], а его предпочтения стабильны и независимы от внешних воздействий. Таким образом, в неоклассической модели hоmо economicus действие индивидов всегда носит характер рационального выбора (совершенная рациональность).

Исходя из предпосылки о том, что рациональность поведения акторов отражается «с одной стороны, в стремлении контролировать ресурсы и соответственно минимизировать их затраты, а с другой стороны, в осуществлении интересов индивида или группы (причем, контроль над ресурсами может выступать как самостоятельная ключевая цель)» [15, с. 129], в целях анализа модели экономического человека Н.Н.Покровская выделяет две переменные как функции эффективности: ресурсы и цели. При этом, если целевая функция обусловлена предметной областью экономической науки, то, согласно практическому опыту, для понимания реального хозяйственного поведения следует учитывать ресурсные ограничения. Границы самой целевой функции, учитывающие неэкономические цели экономического поведения, представляют самостоятельный предмет прочих гуманитарных наук (социология, философия, психология и т.д.).

Рассматривая экономическую теорию как раздел моральной философии, классики политической экономии А.Смит и Дж.С. Милль стремились ограничить целевую функцию, придав ей минимальную социальную обусловленность за счет социальных норм и прочих регуляторов, сдерживающих импульсы индивида. Так, в своей более ранней работе «Теория нравственных чувств» (1759) А. Смит настаивал на том, что не только корыстные интересы управляют человеческим действием: мирное сосуществование индивидуумов в обществе обеспечивается благодаря заложенным в них от природы чувствам симпатии, сострадания, долга, а также присутствию в каждом совести как внутреннего бесстрастного наблюдателя. В этой связи, «невидимая рука» уравновешивает рынок в рамках интернализированных моральных ограничений: «Человек несет общество в самом себе, он утверждает как часть самого себя общественные нормы, оценки и чувства других людей» [21, с. 121]. Наличие в классической модели homo economicus концепции социальной рациональности обусловило тенденцию в зарубежной литературе к выделению в работах представителей классической политической экономии предпосылок институционального анализа [38], [31], [43].

Основываясь на фундаментальной предпосылке о редкости экономических благ, неоклассическая экономическая теория признает подверженность ограничениям ресурсного элемента эффективности. Кроме того, учитывается наличие когнитивных рамок, ограничивающих экономическое поведение набором имеющихся знаний [34]. При характеристике данной концепции экономического человека, О. Уильямсон [37] использует термин органической рациональности, степень которой находится у представителей австрийской школы на порядок ниже, чем у математической за счет включения в модель когнитивных параметров. Причиной «незнания» у хозяйственных субъектов выступает неопределенность [40].

Признавая подверженность ограничениям ресурсного компонента рациональности в усло- 
виях многоаспектной окружающей среды и основываясь на принципах методологического индивидуализма, неоинституционалисты внедрили в свою теорию ряд концепций, приблизив модель неограниченно рационального homo economicus к реальности. Данная модель в научной литературе носит название человека институционального или homo institutius [26] и основана на следующих ресурсных ограничениях функции эффективности, которые выполняют функцию генерации и поддержки институционального равновесия: 1) ограниченная рациональность; 2) транзакционные издержки; 3) когнитивные рамки; 4) референтные рамки; 5) институты.

Согласно неоинституционализму рационального выбора, стремясь к максимизации собственной функции полезности, индивиды действуют в условиях неполной информации и перерабатывают ее при помощи субъективных моделей (предрассудков, представлений и т.д.), а также в силу своих физических способностей (память, интеллект и т.п.), в связи с чем интерпретация информации зачастую носит ошибочный характер. Данные факторы, служащие источниками формирования транзакционных издержек [36], порождают проблему неопределенности, для решения которой индивиды создают институты [16], делая кооперацию возможной.

Формальные и неформальные «правила игры» оказывают прямое влияние на действия экономического субъекта, основным ориентиром при принятии экономических решений для которого становятся институты: производя вычисления полезности, homo economicus «руководствуется в своих оценках и поступках... разумом. <...> У homo institutius «компьютер» локализуется вовне - в институтах. Хотя сам «институциональный человек» может вносить лепту в создание и развитие институтов... он является объектом институционального манипулирования и воздействия» [26, с. 113-114]. Укрепляя уверенность акторов относительно поведения других индивидов, институты служат установлению институционального равновесия.

Между тем, ряд членов научного сообщества при определении предмета новой институциональной экономики не ограничивается рамками теории транзакционных издержек, прав собственности и контрактов. В частности, экономисты Д.Норт и А.Грейф, переосмыслив под- ходы Г.Шмоллера, М.Вебера и Дж. Коммонса, в контексте аппарата когнитивной науки неявно осуществляют возврат к методологии, используемой в рамках интерпретативной парадигмы. Признавая непрерывность и стремительность динамики социальной реальности, Д.Норт наряду с представителями немецкой исторической школы отказывается от разработки стандартных теорий применительно к процессам экономических изменений, «в значительной степени... формируемых осознанием акторами последствий своих действий. <...> Накопленное обучение всего общества, воплощенное в языке, человеческой памяти и системах знакового хранения включает верования, мифы, способы делания различных вещей, что представляет собой культуру общества» [35, с. 8,9]. А. Грейф подчеркивает, что предложенный им социоэкономический подход к анализу институтов «позволяет преодолеть пропасть между изучением институтов как правил или контрактов (как это принято в экономике) и изучением их как культурных феноменов (как это принято в других общественных науках)» [5, с. 73].

Тем не менее, Д.Норт и А.Грейф остались в рамках классической парадигмы [8], [4]. ПоД.Норту эффективность институтов и верований связана со способностью продуцировать экономический рост и снижать транзакционные издержки [норт 1997]. Оставив за рамками социальные конфликты и последствия для окружающей среды, данный подход не ориентирован на комплексное видение экономической деятельности, что выступает одним из важнейших условий институционального анализа согласно интерпретативной парадигме. Кроме того, подчеркнув роль культуры в обучении и принятии экономических решений, неоинституционализм рационального выбора не представляет объяснение возникновению и динамике неформальных институтов: как отмечает Д.Норт, «мы еще не можем во всех деталях объяснить действие сил, определяющих развитие культуры, очевидно, что культурные характеристики общества с течением времени меняются, и что в этом играют роль и случайности, и обучение, и естественный отбор» [16, с. 113].

Новая институциональная экономика, признав исходное положение о том, что индивиды в процессе принятия решений мотивированы стремлением получить личную выгоду, «не позволяет искать истоки совместных действий 
индивидов в культурных, социальных или политических традициях [12, с. 111]. По мнению П. Ульриха, современной экономической теории необходим переход к «цивилизованной рыночной экономике», что требует смены парадигмы на социально-экономическую рациональность [45].

В.В.Вольчик и Т.А.Зотова предлагают использовать предпосылку адаптивной рациональности для исследования экономического поведения в условиях ненулевых транзакционных издержек. В контексте адаптивной рациональности «индивиды не только следуют правилам, содержащимся в институтах, но и получают релевантную для себя информацию для принятия решений» [3, с. 56]. Основное различие между моделями ограниченной и адаптивной рациональности заключается в том, что последняя не предполагает стремления к выбору оптимального варианта, акцентируя внимание на процессе мышления, обучения и взаимообусловленности действий хозяйственных субъектов, соотносящих свои желания с интересами группы.

В числе неортодоксальных течений современной экономической мысли, основанных на том же виде мировоззрения, что и институционалистская традиция Г.Шмоллера и Дж.Коммонса, необходимо особо отметить конструктивистскую (дискурсивную, идейную) институциональную теорию как вариант социологического институционализма [17]. Внося вклад в развитие онтологии интерпретативной парадигмы, данное направление более ориентировано на описание реального экономического поведения [8], [3], комплексной институциональной эволюции, адаптации и инновации [13].

Рассматривая в основе институтов или поведенческих моделей смыслы ситуаций и социальные ценности, разделяемые членами сообщества в данном месте и в данное время [23], [33], [27], [28], представители конструктивистской методологии оспаривают нортоновское и грейфовское понимание институтов в качестве исключительно экзогенных ограничений (constraints), накладываемых на человеческую деятельность и выполняющих функцию социального контроля благодаря наличию механизма принуждения (enforcement). Так, П. Бергер и
Т.Лукман, в духе Г.Шмоллера отмечают, что «первичный социальный контроль задан существованием института как такового. <...> Дополнительные механизмы контроля требуются лишь в том случае, если процессы институционализации не вполне успешны» [2, с. 92]. Таким образом, с точки зрения интерпретативной институциональной экономики институт представляет собой совокупность как экзогенных, так и эндогенных стимулов, оказывающих влияние на целеполагание при принятии экономических решений.

В связи с вышесказанным, представляется обоснованной критика со стороны Г. Б. Клейнера в отношении «бинарных» трактовок института, утверждающего [10], что устойчивость нормы в большинстве случаев обусловлена причинами, выходящими за рамки понятия механизмов принуждения. Разделяя позицию Т.Н. Савиной и Я.В.Бабаяна, мы считаем целесообразным определять «механизмы исполнения» [19] или «способы соблюдения» [1] соответствующего правила в качестве элемента института как экзогенного фактора при принятии экономических решений. Кроме того, целесообразно определять институт как правило, которое выполняется в рамках определенной социальной группы.

Говоря о различиях классической и интерпретативной парадигм применительно к экономической теории институтов (см. табл. 1), необходимо отметить, что в то время как новая институциональная школа применяет инструменты сравнительно-статического и вероятностного анализа для оценки результатов рационального выбора отдельных акторов, подход сторонников интерпретативной парадигмы основан на исследовании успешности институционализации, которая предполагает достижение соответствия института смыслам, верованиям и привычкам всей совокупности участников взаимодействия, конструирующих поведение в сложной и разнонаправленной институциональной среде. В этой связи, изучение эволюции человека в контексте конкретной культуры и сообщества, существующего в определенное время, диктует необходимость подключения исторического метода. 
Таблица 1. Сравнительный анализ классической и интерпретативной парадигм применительно к экономической теории институтов

\begin{tabular}{|l|l|}
\hline Естественнонаучная парадигма & Интерпретативная парадигма \\
\hline Новый институционалм & Исходный институционализм \\
\hline Мировоззрение, основанное на понятии «индивид» & $\begin{array}{l}\text { Коммунитаристское мировоззрение (от понятия } \\
\text { «сообество») }\end{array}$ \\
\hline Индивидуализм & Холизм \\
\hline $\begin{array}{l}\text { Количественный анализ, } \\
\text { индуктивный метод }\end{array}$ & $\begin{array}{l}\text { Качественный анализ, } \\
\text { дедуктивный метод }\end{array}$ \\
\hline Ориентация на результат хозяйственного выбора & $\begin{array}{l}\text { Ориентация на процесс принятия экономического } \\
\text { решения }\end{array}$ \\
\hline $\begin{array}{l}\text { Институт как экзогенное ограничение, налагаемое на } \\
\text { социальные отношения }\end{array}$ & $\begin{array}{l}\text { Институт как эндогенный и экзогенный фактор, } \\
\text { роде }\end{array}$ \\
\hline $\begin{array}{l}\text { Основанющй отношения между людьми и к при- } \\
\text { ческой теории }\end{array}$ & $\begin{array}{l}\text { Отрицание постулатов неоклассической экономиче- } \\
\text { ской теории }\end{array}$ \\
\hline $\begin{array}{l}\text { Преследование собственных интересов из соображе- } \\
\text { ний рациональности }\end{array}$ & $\begin{array}{l}\text { Следование правилам, основанным на разделяемых } \\
\text { сообществом убеждениях и привычках мысли }\end{array}$ \\
\hline $\begin{array}{l}\text { Оценка эффективности в терминах экономического } \\
\text { роста и транзакционных издержек }\end{array}$ & $\begin{array}{l}\text { Оценка дистрибутивных последствий институциона- } \\
\text { лизации }\end{array}$ \\
\hline
\end{tabular}

Источник: составлено автором.

\section{Библиографический список}

1. Бабаян, Я. В. Комплекс государственно-властных воздействий на преобразование институциональной среды / Я. В.Бабаян // Научный вестник ЮИМ. - 2015. - № 1. - С. 68-72.

2. Бергер П., Лукман Т. Социальное конструирование реальности. Трактат по социологии знания. М.: «Медиум», 1995. - С. 92.

3. Вольчик B.B., Зотова Т.А. Адаптивная рациональность и экономическое поведение в эволюционном контексте // TERRA ECONOMICUS, 2011, Том 9, № 4. - С. 56.

4. Вольчик В.В., Филоненко Ю.В., Кривошеева-Медянцева Д.Д. Адаптивная рациональность, адаптивное поведение и институты // JOURNAL OF INSTITUTIONAL STUDIES (Журнал институциональных исследований) Том 7, № 4, 2015. - С. 145.

5. Грейф А. Институты и путь к современной экономике. Уроки средневековой торговли / А. Грейф - «Всшая Школа Экономики (ВШЭ)», 2006 - (Экономическая теория (ГУ ВШЭ). - С. 73.

6. Джевонс У.С. Краткое сообщение об общей математической теории политической экономии // Теория потребительского поведения и спроса / Под ред. В. М. Гальперина. СПб., 1993.

7. Дюркгейм Э. Социология. Ее предмет, метод, предназначение / Пер. с фр., составление, послесловие и примечания А. Б. Гофмана. - М.: Канон, 1995.- 352 с.

8. Ефимов В.М. Об интерпретативной институциональной экономике (научный доклад). Институт экономики РАН, М.: 2007. - С. 31.

9. Ефимов В.М. От машин удовольствия к моральным сообществам (размышления над новой книгой Джеффри Ходжсона) // JOURNAL OF INSTITUTIONAL STUDIES (Журнал институциональных исследований), Т. 5, № 2, 2013. - С. 17.

10. Клейнер, Г.Б. Эволюция институциональных систем / Г.Б. Клейнер. - М.: Наука, 2004. - 240 с.

11. Коммонс Дж. Институциональная экономика // Terra Economicus, T. 10, № 3, 2012. - С. 69-76.

12. Кутырев Г.И. Неоинституционализм рационального выбора: преимущества и внутренние противоречия // Исторические, философские, политические и юридические науки, культурология и искусствоведение. Вопросы теории и практики. Тамбов: Грамота, 2012 № 11 (25), Ч. І. - С. 111.

13. Ляпичев С. А. Реформа ООН и международное сотрудничество: дис. ... канд. полит. наук: 23.00.04 / Ляпичев Семен Александрович. - Москва, 2012. - 200 с. 
14. Мировая экономическая мысль. Сквозь призму веков: в 5 т. / Моск. гос. ун-т им. М В. Ломоносова, Благотвор. фонд «Благосостояние для всех»; [науч.-ред. совет: Г. Г. Фетисов (сопред.), А. Г. Худокормов (сопред.) и др.]. Том. III. Эпоха социальных переломов. Москва: Мысль, 2004-2005. - 896 с. - С. 334.

15. Н.Н. Покровская. Рациональность экономического поведения // Известия Российского государственного педагогического университета им. А. И. Герцена - Т.9, № 46 (2007). - С. 129.

16. Норт Дуглас. Институты, институциональные изменения и функционирование экономики. Пер. с англ. А.Н.Нестеренко; предисл. и науч. ред. Б. З. Мильнера. - М.: Фонд экономической книги “Начала”, 1997. 180 с. - (Современная институционально-эволюционная теория). - С. 113.

17. Панов П. В. Институционализм(ы): объяснительные модели и причинность // ПОЛИС. ПОЛИТИЧЕСКИЕ ИССЛЕДОВАНИЯ № 3 (2015). - С. 175.

18. Пирс Ч. С. Избранные произведения. М.: Логос. 2000 - С. 274-278, 305.

19. Савина, Т.Н. Роль институциональной среды в условиях инновационного развития экономики России / Т.Н. Савина // Финансы и кредит. - 2012. - № 35 (515). - С. 59-68.

20. Смит А. Исследование о природе и причинах богатства народов / А. Смит - «Эксмо», 1776 - С. 350.

21. Смит А. Теория нравственных чувств/Вступ. ст. Б. В. Мееровского; Подгот. текста, коммент. А.Ф.Грязнова. - М.: Республика, 1997.- 351 с. - С. 121.

22. Торстейн Веблен: Теория праздного класса: экономическое исследование институций. - Перевод с английского. Вступительная статья кандидата экономических наук С. Г. Сорокиной. Общая редакция доктора экономических наук В. В. Мотылёва. - М., 1984. - С. 107, 109.

23. Флигстин Н. Поля, власть и социальные навыки: критический анализ новых институциональных течений // Экономическая социология: Новые подходы к институциональному и сетевому анализу. - М.: Российская политическая энциклопедия (РОССПЭН), 2002. - С. 119-156.

24. Ходжсон Д. Экономическая теория и институты. М.: Дело. 2003. - С. 53.

25. Шмоллер, Г. Народное хозяйство, наука о народном хозяйстве и ее методы. - Хозяйство, нравы и право. Разделение труда / Г.Шмоллер. - М.: Типо-лит. В. Рихтеръ, 1902. - 366, XII, XII с. - С. 137-138.

26. Homo institutius - человек институциональный [монография] / под ред. д-ра экон. наук О.В.Иншакова. Волгоград: Изд-во ВолГу, 2005. - 854 с. - С. 113-114.

27. Berger P. and T. Luckman. The Social Construction of Reality, London: Penguin Books. 1991.

28. Bromley D. W. Sufficient Reason. Volitional Pragmatism and the Meaning of Economic Institutions. Princeton: Princeton University Press. 2006.

29. Chavance B. John Commons's organizational theory of institutions: a discussion. Journal of Institutional Economics, 2012, vol. 8, no 1, pp. 27-47

30. Commons J.R. The problem of correlating law, economics and ethics. Wisconsin Law Review, vol. 8, December, 1932, pp. 3-26.

31. Evensky, Jerry. Adam Smith’s Lost Legacy.” Southern Economic Journal, vol. 67, no. 3, Southern Economic Association, 2001, pp. 497-517.

32. Gonzalo Caballero \& David Soto-Oñate. The Diversity and Rapprochement of Theories of Institutional Change: Original Institutionalism and New Institutional Economics, Journal of Economic Issues, 2015. 947-977. - P. 961.

33. McCloskey D. N. Bourgeois dignity: Why economics can't explain the modern world, Chicago, University of Chicago Press, 2010.

34. Menger C. Investigations into the Method of the Social Sciences with Special Reference to Economics / Transl. by F. Nock. New York, 1985. - P. 84.

35. North D. C. Understanding the Process of Economic Change. Princeton and Oxford: Princeton University Press. 2005. - P. 8-9.

36. North D., Wailis J. Measuring the Transactional Sector in the American Economy, 1870-1970// Long-Term Factors in American Economic Growth. Chicago: University of Chicago Press, 1986.

37. Oliver E. Williamson. Behavioral Assumptions. In: O. E. Williamson. The Economic Institutions of Capitalism. Firms, Markets, Relational Contracting. N.Y.: The Free Press, 1985, p.44-52

38. Perri, Stefano, and Enzo Pesciarelli. Adam Smith on the relationship between town and country: pitfalls in the use of formal models in the history of economics. A rejoinder. History of Economic Ideas, vol. 6, no. 3, Accademia Editoriale, 1998, pp. 197-205.

39. Prisching, Manfred. Schmoller's theory of society. History of Economic Ideas, vol. 1/2, no. 3/1, Accademia Editoriale, 1993, pp. 117-42.

40. Schmoller, Gustav. Besprechung von Karl Bucher, Die Entstehung der Volkswirtschaft, 1893, Schmollers Jahrbuch, 17, pp. 301-306. 
41. Schmoller, Gustav. Grundriss der Allgemeinen Volkswirtschaftslehre. Erster Teil. Leipzig: Verlag von Duncker \& Humblot. 1920, pp. 61-62.

42. Schneider L. Preface to: K. Menger. Problems of Economics and Sociology. Urbana: University of Illinois Press, 1963.

43. Tajima, Keigo. The theory of institutions and collective action in Adam Smith's Theory of Moral Sentiments. Journal of Socio-Economics, 2007, 36 (4).

44. Tilman, Rick. Thorstein Veblen and the Enrichment of Evolutionary Naturalism. Columbia, MO: University of Missouri Press, 2007.

45. Ulrich P. Integrative Economic Ethics. Foundations of a Civilized Market Economy. Cambridge: Cambridge University Press, 2010.

46. Veblen T. The Place of Science in Modern Civilization. New Brunswick: Transaction Publishers. 1990. - P.77.

47. Veblen, Thorstein B. Review of Pure Sociology: A Treatise Concerning the Origin and Spontaneous Development of Society by Lester Ward, Journal of Political Economy, 1903, 11(4), September. - P. 655. 